\title{
Assessment of therapeutic safety in systematic reviews: literature review
}

\author{
Edzard Ernst, Max H Pittler
}

Department of Complementary Medicine, School of Postgraduate Medicine and Health Sciences, University of Exeter, Exeter EX2 4NT Edzard Ernst director

Max H Pittler research fellow Correspondence to: E Ernst

E.Ernst@exeter. acuk

BMJ 2001;323:546
Evidence based medicine aims to objectively and continually evaluate all medical interventions with a view to incorporating the knowledge gained into routine healthcare practice. The ultimate goal is to enhance patient care. The most powerful tools used in evidence based medicine are systematic reviews and metaanalyses. ${ }^{1}$ Generally, these studies focus on the efficacy or effectiveness of therapeutic interventions; indisputably, however, information on safety is equally important for making informed, evidence based decisions on the value of a given treatment. We evaluated two major medical databases to assess the extent to which therapeutic safety is addressed in systematic reviews and meta-analyses.

\section{Methods and results}

We performed systematic literature searches to identify all systematic reviews and meta-analyses on the efficacy or effectiveness and the safety of any type of therapeutic intervention. Data sources were Medline (1966-December 2000) and the Cochrane Library (2000, issue 4). The title, abstract, and keywords of papers were searched using the terms efficacy, effectiveness, systematic review, meta-analysis, safety, adverse effect, adverse event, and adverse reaction and their derivatives. No language restrictions were imposed. The title and abstract of all studies were read and data were according to the criteria defined. Studies were included only if they stated that they were systematic reviews or meta-analyses or if they indicated that the available data were systematically searched for, appraised, and summarised. Studies that included no abstract or that provided no data on humans were excluded. Data were assessed according to the year of the study, and the studies were categorised into three categories: systematic reviews on efficacy or effectiveness, systematic reviews that

Systematic reviews and meta-analyses of therapeutic interventions in Medline and the Cochrane Library. Values are numbers (percentages) of trials

\begin{tabular}{|c|c|c|c|c|}
\hline \multirow[b]{2}{*}{ Time period } & \multirow[b]{2}{*}{ Source } & \multirow{2}{*}{$\begin{array}{l}\text { Efficacy or } \\
\text { effectiveness }\end{array}$} & \multicolumn{2}{|c|}{ Safety } \\
\hline & & & Safety Category A & Safety Category B \\
\hline \multirow[t]{2}{*}{ 1966-70 } & Medline & 0 & 0 & 0 \\
\hline & Cochrane Library & 1 & 0 & 0 \\
\hline \multirow[t]{2}{*}{ 1971-75 } & Medline & 0 & 0 & 0 \\
\hline & Cochrane Library & 0 & 0 & 0 \\
\hline \multirow[t]{2}{*}{ 1976-80 } & Medline & 1 & 0 & $1(100)$ \\
\hline & Cochrane Library & 2 & 0 & 0 \\
\hline \multirow[t]{2}{*}{ 1981-85 } & Medline & 11 & 0 & 0 \\
\hline & Cochrane Library & 12 & 0 & 0 \\
\hline \multirow[t]{2}{*}{ 1986-90 } & Medline & 103 & $10(10)$ & $5(5)$ \\
\hline & Cochrane Library & 71 & $8(11)$ & $3(4)$ \\
\hline \multirow[t]{2}{*}{ 1991-95 } & Medline & 431 & $60(14)$ & $19(4)$ \\
\hline & Cochrane Library & 406 & $61(15)$ & $12(3)$ \\
\hline \multirow[t]{2}{*}{ 1996-December 2000} & Medline & 1005 & $259(26)$ & $41(4)$ \\
\hline & Cochrane Library & 1462 & $398(27)$ & $54(4)$ \\
\hline
\end{tabular}

Category $A=s t u d y$ included safety as a secondary outcome measure. Category $B=s t u d y$ included safety as a primary focus. included safety aspects as a secondary outcome measure (safety category A), and systematic reviews with a primary focus on the safety of the therapy (safety category B). Study selection, data extraction, and evaluation were performed independently by the two investigators, and discrepancies were resolved through discussion.

The results (table) showed a continuous increase in the number of systematic reviews and meta-analyses published between 1966 and December 2000. The number of studies that included safety aspects as a secondary outcome measure (category A) amounted to just over one quarter of the total number of studies on efficacy or effectiveness. The number of systematic reviews that assessed safety aspects as the primary focus of the investigation (category $\mathrm{B}$ ) amounted to only $3-5 \%$ (table).

\section{Comment}

Systematic reviews and meta-analyses provide little information on the safety aspects of therapeutic interventions. Most systematic reviews include data on safety only in as much as the primary studies, usually randomised clinical trials, report on adverse events. This seems inadequate. Randomised clinical trials typically assess only a small number of patients and thus the chances of detecting rare adverse events are small. Randomised clinical trials are usually of short duration and thus cannot identify delayed adverse events. ${ }^{2}$ The assessment of safety has to go far beyond randomised clinical trials and should use various methods, including post-marketing surveillance studies, spontaneous reporting schemes, and epidemiological investigations. ${ }^{3}$ Systematic reviews on the safety of therapeutic interventions should take these considerations into account and should combine data from various types of studies. ${ }^{4}$ Safety aspects have so far not been adequately investigated by systematic reviews. One challenge of evidence based medicine therefore is to address safety issues more systematically than has been done before.

Contributors: EE conceived the idea of the study. EE and MHP planned the design, reviewed the original data, evaluated the results, and wrote up the report. $\mathrm{EE}$ is the guarantor of the paper.

Funding: None.

Competing interests: None declared.

1 Mulrow C. Rationale of systematic reviews. BMJ 1994;309:597-99.

2 Rawlins MD. Pharmacovigilance: paradise lost, regained or postponed? JR Coll Physicians Lond 1995;29:41-9.

3 Ernst E, Barnes J. Methodological approaches to investigating the safety of complementary medicine. Complement Ther Med 1998;6:115-21.

4 Stevinson C, Ernst E. Safety of hypericum in patients with depression. CNS Drugs 1999;11:125-32.

(Accepted 22 March 2001) 


\section{Drug points}

\section{Diabetes inspidus induced by ofloxacin}

Anil Bharani, Hrishikesh Kumar, Department of Medicine, MGM Medical College and MY Hospital, Indore 452001, India

Nephrogenic diabetes insipidus occurs with agents such as lithium, methoxyfluorane, vitamin $\mathrm{D}$, and demeclocycline. ${ }^{12}$ We report a case of diabetes insipidus induced by ofloxacin (Tarivid; Hoescht Marion Roussel).

A 25 year old man was admitted with fever, a dry cough, and dyspnoea of three days' duration. He had had an influenza-like illness in the preceding week, and his doctor had prescribed ampicillin $2 \mathrm{~g}$ daily for three days. On examination he was febrile, toxic, dyspnoeic, and had poor oral hygiene. His pulse was 130 beats/min, blood pressure $110 / 70 \mathrm{~mm} \mathrm{Hg}$, and respiration 35 breaths/min. A chest examination showed signs of bilateral lobar consolidation of the mid zones. His total white blood cell count was $20 \times 10^{9} / 1$ with $90 \%$ polymorphs, the results of blood biochemistry were normal, and he had negative results for hepatitis B surface antigen, HIV-1, and HIV-2. A chest $x$ ray film showed bilateral lobar infiltrates, no pleural reaction, and a normal cardiac silhouette. We diagnosed "typical" bilateral lobar pneumonia acquired in the community after influenza. He was treated with multiple antibiotics as sputum and relevant bacteriology results could not be obtained: penicillin G 2 million units four times daily, gentamicin $60 \mathrm{mg}$ every eight hours, clarithromycin 500 $\mathrm{mg}$ twice daily, and metronidazole $400 \mathrm{mg}$ every eight hours. He was also given a mucolytic, intravenous fluids, vitamins, and intranasal oxygen.

On the third day after admission his response was poor and he was given ofloxacin $200 \mathrm{mg}$ twice daily. $\mathrm{He}$ seemed to improve, but on the fifth day he developed polyuria $(>20$ 1/day) with excessive thirst (urine 264
$\mathrm{mOsmol} / \mathrm{kg}$ with urinary sodium excretion $286 \mathrm{mmol} /$ day). Ofloxacin induced diabetes insipidus was suspected, and the drug was stopped. His urine volume gradually decreased and his thirst normalised within 36 hours while the other drugs were continued. As he continued to improve we rechallenged him with ofloxacin $400 \mathrm{mg}$ daily. Again his urine production increased in association with polydipsia. Ofloxacin was stopped. A chest $x$ ray film showed resolution of the pneumonic consolidation. Multiple cavity formation bilaterally suggested infection with Staphylococcus aureus. He was given ceftriazone $2 \mathrm{~g}$ daily and cloxacillin $500 \mathrm{mg}$ four times daily. His symptoms resolved after two weeks.

That the diabetes insipidus recurred when he was rechallenged with ofloxacin and resolved after the drug was stopped while other treatment was continued suggests a causal relation. We could find no report on ofloxacin induced diabetes insipidus in the published literature or from the product monograph. We reported this side effect to the manufacturer and the Central Drug Standard Control Organisation (west zone), both of which were unaware of any such report. Similarly, the other drugs the patient took were unlikely to interact to cause a diabetes insipidus-like syndrome. The mechanism of this interaction is not clear; it could be similar to that of lithium or demeclocycline, which interferes with the action of antidiuretic hormone on the collecting ducts. ${ }^{12}$

Competing interests: None declared.

1 Moses AM, Streeten DHP. Disorders of the neurohypophysis. In Isselbacher KJ, Braunwald E, Wilson JD, eds. Harrison's principles of internal medicine, 13th ed. NewYork: McGraw-Hill, 1994:1921-30.

2 Forrest JN Jr, Cox IM, Hong C, Morrison G, Bia M, Singer I. Superiority of demeclocycline over lithium in the treatment of chronic syndrome of inappropriate secretion of antidiuretic hormone. $N$ Engl $J$ Med 1978;298:173-7.

\section{The skills it takes}

The practice of medicine can take all forms, and the diversity and adaptability that we sometimes require continue to amaze and intrigue me. In my short career I have had strange requests and patients, from seeing a Sioux child who had been shot by an arrow and delivering babies in hospital car parks to learning about and adapting to the world of molecular biology. None prepared me for a request that I received while working as a resident medical officer at a private hospital during the present foot and mouth outbreak.

An embarrassed nurse knocked on the door of my on call room and asked whether I had any shepherding experience. She had been looking out of the window and noticed that the lambs in the neighbouring field had escaped through the fence. Concerned, she had called reception to ask for the telephone number of the local farmer, so that she could inform him of his escapees. "Don't worry," replied the receptionist, "the RMO will do it, he's done it before." Indeed, the week before, she had found me in the car park ushering a lamb back into the field after a breakout. There were bemused patients peering from the window as their resident doctor was seen patrolling the fence and chasing the lambs back in to the field.

I bumped into one of the professors in the corridor later and told him of my exploits; he laughed and replied, “I hope you didn't get caught. We can't have you being arrested for illegally transporting livestock."

I can now add shepherd to the many skills that I have had to call on in my practice as a doctor.

James Clover clinical research fellow, Ratby, Leicestershire

We welcome articles up to 600 words on topics such as A memorable patient, A paper that changed my practice, My most unfortunate mistake, or any other piece conveying instruction, pathos, or humour. If possible the article should be supplied on a disk. Permission is needed from the patient or a relative if an identifiable patient is referred to. We also welcome contributions for "Endpieces," consisting of quotations of up to 80 words (but most are considerably shorter) from any source, ancient or modern, which have appealed to the reader. 